\title{
DWI-Based Algorithm to Predict Disability in Patients Treated with Thrombectomy for Acute Stroke
}

\author{
(D). Raoult, (DM.V. Lassalle, (D)B. Parat, (D). Rousseau, (D). Eugène, (D). Vannier, (DS. Evain, (D) A. Le Bras, (D). Ronziere,
} (D).C. Ferre, DJ.Y. Gauvrit, and (D)B. Laviolle

\begin{abstract}
BACKGROUND AND PURPOSE: The reasons for poor clinical outcome after thrombectomy for acute stroke, concerning around half of all patients, are misunderstood. We developed a hierarchic algorithm based on DWI to better identify patients at high risk of disability.
\end{abstract}

MATERIALS AND METHODS: Our single-center, retrospective study included consecutive patients with acute ischemic stroke who underwent thrombectomy for large anterior artery occlusion and underwent pretreatment DWI. The primary outcome was the $\mathrm{mRS}$ at 3 months after stroke onset. Multivariable regression was used to identify independent clinical and imaging predictors of poor prognosis (mRS $>2$ ) at 3 months, and a hierarchic algorithm predictive of disability was developed.

RESULTS: A total of 149 patients were analyzed. In decreasing importance, DWI lesion volume of $>80 \mathrm{~mL}$, baseline NIHSS score of $>14$, age older than 75 years, and time from stroke onset to groin puncture of $>4$ hours were independent predictors of poor prognosis. The predictive hierarchic algorithm developed from the multivariate analysis predicted the risk of disability at 3 months for up to $100 \%$ of patients with a high predictive value. The area under the receiver operating characteristic curve was 0.87 .

CONCLUSIONS: The DWI-based hierarchic algorithm we developed is highly predictive of disability at 3 months after thrombectomy and is easy to use in routine practice.

S troke is one of the leading causes of mortality and disability worldwide. ${ }^{1}$ In recent years, multiple randomized controlled trials have shown that endovascular treatment improves functional outcome in patients with a proximal occlusion of the anterior circulation, ${ }^{2}$ with an efficacy unmatched by any previous therapy for stroke management, given a number needed to treat of $<3$ to achieve improved functional outcome. Endovascular treatment with or without intravenous alteplase yields a high recanalization rate of up to $90 \%^{2,3}$ and is therefore a validated, effective, and safe treatment now recommended for these patients. ${ }^{4,5}$ Current stroke guidelines are based on data from these randomized controlled trials including highly selected patients. Their encouraging results led to more widespread use of endovascular treatment; therefore, broader criteria than

Received August 6, 2019; accepted after revision November 14

From the Departments of Neuroradiology (H.R., B.P., F.E., J.C.F., J.Y.G.), Neurology (M.V.L., S.V., T.R.), and Clinical Pharmacology (C.R., B.L.), Institut National de la Santé et de la Recherche Médicale, Centre d'Investigation Clinique de Rennes, Centre Hospitalier Universitaire Rennes, Rennes, France; and Departments of Neurology (S.E.) and Radiology (A.L.B.), Centre Hospitalier Universitaire Bretagne Atlantique, Vannes, France.

Please address correspondence to Hélène Raoult, MD, PhD, Neuroradiologie, CHU Pontchaillou, 2 Rue Henri Le Guilloux, 35033 Rennes, France; e-mail: helene.raoult@chu-rennes.fr

Indicates article with supplemental on-line photo.

http://dx.doi.org/10.3174/ajnr.A6379 those recommended are now used in current practice to treat, for example, elderly patients, ${ }^{6}$ patients with minimal stroke symptoms, ${ }^{7}$ or patients in late time windows up to 24 hours after stroke onset. ${ }^{8}$ On the other hand, the Highly Effective Reperfusion using Multiple Endovascular Devices (HERMES) meta-analysis of the main trials also highlighted that half of all patients have poor clinical outcomes despite successful technical recanalization. ${ }^{2}$

Because the reasons for poor clinical outcome after thrombectomy are not clearly understood ${ }^{9}$ and given that in clinical practice, patients are often of advanced age and present with high stroke severity or a large ischemic volume, patient selection for thrombectomy warrants improvement. Multiple individual poor prognostic factors may be involved simultaneously. ${ }^{9}$ Several prognostic tools have, therefore, been proposed, ${ }^{10-13}$ based on clinical and radiologic pretreatment criteria to predict the risk of disability after thrombectomy: Mainly advanced age, a high baseline NIHSS score, and a low baseline ASPECTS on noncontrast CT have been identified as reliable predictors of prognosis. However, these studies were conducted before the latest trials and were mainly based on CT but rarely on MR imaging to triage patients. Yet DWI was shown to be more accurate than noncontrast $\mathrm{CT}^{14}$ for estimating the ischemic core and was more accurate than perfusion $\mathrm{CT}$ for predicting final infarct volume. ${ }^{15}$ These findings suggest that DWI would be a better imaging 
parameter than CT for predicting futile outcomes. A recent meta-analysis from the HERMES group ${ }^{16}$ showed that core infarct volume correlated with 3-month clinical outcome and that patients selected by MR imaging, though accounting for only $18 \%$ of cases, had superior outcomes relative to patients selected by CT and CT perfusion estimates of core infarction. The recent THRombectomie des Artéres CErebrales (THRACE) trial used DWI for pretreatment imaging in $70 \%$ of patients, identifying DWI volume as an independent factor predictive of poor outcome and showing the benefit of thrombectomy decreasing with an increase in lesion volume. ${ }^{17}$

The purpose of our study was to develop a hierarchic algorithm based on MR imaging and clinical data to better identify patients who may not benefit from thrombectomy, given the risk of disability.

\section{MATERIALS AND METHODS Study Design and Patients}

This was a retrospective, observational study including all consecutive patients admitted directly to Rennes University Hospital or referred from 3 other general hospitals (Vannes, Saint-Brieuc and Saint-Malo hospitals) between January 2015 and May 2017. The local ethics review board found the research to conform to generally accepted scientific principles and ethical standards (committee decision No. 17.71, December 18, 2017). According to French legislation, no informed consent was required in view of the observational and retrospective nature of this study, and all patients were informed of its purpose and the procedures involved and of their right to refuse use of their data.

Inclusion criteria were the following: patients 18 years of age or older, presenting with acute ischemic stroke with proximal arterial occlusion of the anterior circulation confirmed on 1.5 or $3 \mathrm{~T}$ MR imaging, admitted to our center within 6 hours of symptom onset, and undergoing endovascular treatment with or without intravenous alteplase. Exclusion criteria were the following: posterior circulation stroke on $\mathrm{MR}$ imaging, prestroke $\mathrm{mRS}>2$, and no available prethrombectomy MR imaging or modified $\mathrm{mRS}$ at 3 months after stroke onset (accepted limit, 120 days).

Intravenous thrombolysis was performed within 4.5 hours of stroke onset by intravenous administration of $0.9 \mathrm{mg} / \mathrm{kg}$ of alteplase (maximum, $90 \mathrm{mg}$ ) with an initial bolus of $10 \%$ of the total dose followed by an infusion of the remaining dose during 60 minutes. Endovascular thrombectomy was performed by neurointerventionalists with $>5$ years' experience. At the beginning of the procedure, an intravenous heparin bolus (1500-2000 IU) was administered to patients who did not receive intravenous alteplase. With the patient under conscious sedation or general anesthesia (as determined by the medical team), endovascular treatment was performed using a coaxial ( $6 \mathrm{~F}$ or $8 \mathrm{~F}$ guiding catheter) or triaxial system (long introducer sheath or $8 \mathrm{~F}$ guiding catheter with an intermediate aspiration catheter) and a combined approach with a microcatheter-delivered stent retriever and manual aspiration during stent retrieval (up to 5 passes if necessary).

\section{Clinical and Imaging Data Collection}

The following data were collected at baseline: demographic characteristics (age and sex); history of treated diabetes mellitus, hypertension and/or atrial fibrillation, and history of ischemic stroke and transient ischemic attack; blood glucose level; systolic blood pressure; and NIHSS range of $0-42$, with higher scores indicating more severe neurologic deficits.

The ischemic infarct lesion volume on pretreatment MR imaging was calculated from the ADC of DWI using a semiautomatic segmentation method with an AW Server 3.2 (2106; GE Healthcare, Milwaukee, Wisconsin). The ASPECTS (DWIASPECTS) was determined by a senior neuroradiologist (with $>5$ years' experience). Intracranial occlusion location and infarct side were indicated on MR imaging. We also collected stroke treatment details: intravenous alteplase administration, time from stroke onset to groin puncture, anesthesia type (general anesthesia or conscious sedation), and post-thrombectomy angiographic results according to the TICI grading system, with a score of $2 \mathrm{~b}$ or 3 corresponding to reperfusion of at least $50 \%$ of the affected arterial territory. Symptomatic intracranial hemorrhage at 24 hours was defined as bleeding visible on CT plus an increase in the NIHSS score of at least 4 points. ${ }^{3}$

\section{Statistical Analysis}

Statistical analysis was performed using SAS software 9.4 (SAS Institute, Cary, North Carolina). For continuous variables, the mean $\pm \mathrm{SD}$ is reported, and for categoric variables, the number of patients in each category and the corresponding percentage are given. Patients were divided into 2 groups according to the $\mathrm{mRS}$ at 3 months (poor prognosis, $\mathrm{mRS}>2$; and good prognosis, $\mathrm{mRS} \leq 2$ ). The characteristics of the 2 groups were compared using the Student $t$ test or Wilcoxon rank sum test when appropriate for continuous variables, and the $\chi^{2}$ or Fisher exact test when appropriate for categoric variables. To identify risk factors independently associated with poor prognosis, we entered variables found to be significantly different $(P<.20)$ between the 2 groups into a forward stepwise logistic regression model. Each variable used in this logistic regression analysis was binary. Cutoff values were those with the best sensitivity and specificity found on the receiver operating characteristic curves for each variable. A predictive hierarchic algorithm showing the likelihood of poor prognosis at 3 months was also constructed using the variables in the logistic model at the $P<.01$ level. For all analyses, $P<.05$ was considered statistically significant.

\section{RESULTS}

During the study period, 289 patients underwent endovascular treatment for acute anterior circulation stroke secondary to large intracranial arterial occlusion, and finally a total of 149 patients were included in the analysis (Fig 1).

\section{Population Characteristics}

Table 1 shows baseline characteristics in the 2 groups. A total of 80 patients $(53.7 \%$; $95 \% \mathrm{CI}, 45.3 \%-61.9 \%)$ had a poor prognosis at 3 months ( 20 with $\mathrm{mRS}=3$, seventeen with $\mathrm{mRS}=4$, five with $\mathrm{mRS}=5$, and 38 with $\mathrm{mRS}=6$ ). Compared with patients with good prognoses, patients with poor prognoses at 3 months were older; had a more frequent history of hypertension and atrial fibrillation; and had higher blood glucose levels, a higher NIHSS score at baseline, a higher DWI lesion volume and DWI- 
ASPECTS, and more terminal internal carotid artery occlusions. Stroke treatment details showed that compared with patients with good prognoses, patients with poor prognoses at 3 months were less often treated with intravenous alteplase, had general anesthesia more often, and had a longer time from stroke onset to groin puncture and a higher rate of recanalization failure. Successful recanalization (as assessed by a TICI score of $2 \mathrm{~b}$ or 3 ) was achieved in 122 patients $(81.9 \%$; $95 \% \mathrm{CI}$, $74.7 \%-87.7 \%)$. Symptomatic intracranial hemorrhage was observed in 5 patients $(4.3 \%)$ of a total 117 patients with available data.

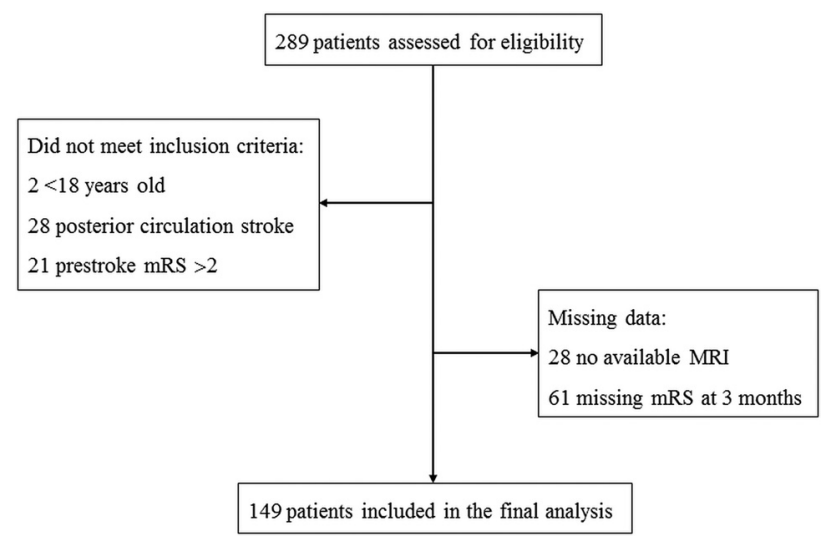

FIG 1. Flow chart.

\section{Prognostic Factors}

Multivariate logistic regression analysis identified 4 independent risk factors of poor prognosis at 3 months, which were in decreasing importance: DWI lesion volume $>80 \mathrm{~mL}$, baseline NIHSS score $>14$, age older than 75 years, and time from stroke onset to groin puncture of $>4$ hours (Table 2). The predictive quality of the logistic model was high, as illustrated by an area under the receiver operating characteristic curve of 0.87 with a $95 \%$ CI, $0.81-$ 0.93 (Fig 2). DWI volume of $80 \mathrm{~mL}$ had the best sensitivity and specificity with an area under the receiver operating characteristics curve of 0.71 (a patient with a DWI lesion of $>80 \mathrm{~mL}$ had $96.8 \%$ of risk of poor outcome, and a patient with a DWI lesion of $\leq 80 \mathrm{~mL}$ had a $61.8 \%$ of chance of good outcome). For DWIASPECTS, the area under the receiver operating characteristics curve was 0.73 , and a patient with a score of $<5$ had $84.8 \%$ of risk of poor outcome, whereas a patient with an ASPECTS of $\geq 5$ had a $60.2 \%$ of chance of good outcome. A close relationship was observed between DWI-ASPECTS and DWI lesion volume with a correlation coefficient of 0.87 (plot in On-line Figure). Only DWI volume was a significant predictor with a relative difference in means between the good and poor prognosis groups of $61 \%$ (31\% for DWI-ASPECTS).

We developed a hierarchic algorithm, with the variables entered in the model at the $P<.01$ level showing the proportion of poor prognoses at 3 months predicted with the model and the corresponding number of patients with poor prognoses observed in our population (Fig 3). The percentage of poor prognoses was

Table 1: Characteristics of the study population ${ }^{\mathrm{a}}$

\begin{tabular}{|c|c|c|c|c|}
\hline Variable & $\begin{array}{c}\text { Total } \\
(n=149)\end{array}$ & $\begin{array}{c}\text { Good Prognosis: mRS at } \\
3 \text { Months } \leq 2(n=69)\end{array}$ & $\begin{array}{l}\text { Poor Prognosis: mRS at } \\
3 \text { Months }>2(n=80)\end{array}$ & $\begin{array}{c}P \\
\text { Value }\end{array}$ \\
\hline Age (yr) & $68.7 \pm 14.3$ & $65.8 \pm 15.1$ & $71.2 \pm 13.2$ & .022 \\
\hline Sex ratio (female/male) & 71:78 & $32: 37$ & $39: 41$ & .772 \\
\hline Diabetes mellitus & 15 (10.1\%) & $4(5.8 \%)$ & $11(13.8 \%)$ & .108 \\
\hline Arterial hypertension & $88(59.1 \%)$ & $33(47.8 \%)$ & $55(68.8 \%)$ & .010 \\
\hline Atrial fibrillation & $37(24.8 \%)$ & $10(14.5 \%)$ & $27(33.8 \%)$ & .007 \\
\hline History of stroke or transient ischemic attack & $25(16.8 \%)$ & $8(11.6 \%)$ & $17(21.3 \%)$ & .116 \\
\hline Prestroke mRS & & & & .670 \\
\hline 0 & $137(91.9 \%)$ & $65(94.2 \%)$ & $72(90.0 \%)$ & \\
\hline 1 & $10(6.7 \%)$ & $3(4.3 \%)$ & $7(8.8 \%)$ & \\
\hline 2 & $2(1.3 \%)$ & $1(1.4 \%)$ & $1(1.3 \%)$ & \\
\hline Systolic blood pressure (mm Hg) & $153.4 \pm 27.6$ & $155.7 \pm 28.3$ & $151.3 \pm 27.0$ & .372 \\
\hline Blood glucose level (mmol/L) & $6.9 \pm 2.2$ & $6.3 \pm 1.3$ & $7.4 \pm 2.6$ & .001 \\
\hline Baseline NIHSS score & $16.3 \pm 5.4$ & $13.8 \pm 5.6$ & $18.5 \pm 4.2$ & $<.001$ \\
\hline DWI-ASPECTS & $5.9 \pm 2.7$ & $7.1 \pm 2.1$ & $4.9 \pm 2.7$ & $<.001$ \\
\hline DWI volume (mL) & $53.3 \pm 64.8$ & $23.8 \pm 18.7$ & $81.1 \pm 79.2$ & $<.001$ \\
\hline Occlusion location & & & & $<.001$ \\
\hline $\mathrm{Ml}$ & $95(63.8 \%)$ & $45(65.2 \%)$ & $50(62.5 \%)$ & \\
\hline $\mathrm{M} 2$ & $21(14.1 \%)$ & $18(26.1 \%)$ & $3(3.8 \%)$ & \\
\hline Terminal ICA & $33(22.1 \%)$ & $6(8.7 \%)$ & $27(33.8 \%)$ & \\
\hline Intravenous alteplase & $115(77.2 \%)$ & $60(87.0 \%)$ & $55(68.8 \%)$ & .008 \\
\hline Stroke side & & & & .304 \\
\hline Left & $65(43.6 \%)$ & 27 (39.1\%) & $38(47.5 \%)$ & \\
\hline Right & $84(56.4 \%)$ & $42(60.9 \%)$ & $42(52.5 \%)$ & \\
\hline Time from stroke onset to groin puncture (hr) & $3.9 \pm 1.3$ & $3.6 \pm 1.2$ & $4.2 \pm 1.3$ & .002 \\
\hline Recanalization score & & & & .019 \\
\hline $\mathrm{TICl} 2 \mathrm{~b} / 3$ & $122(81.9 \%)$ & $62(89.9 \%)$ & $60(75.0 \%)$ & \\
\hline $\mathrm{TICl} 0 / 1 / 2 \mathrm{a}$ & $27(18.1 \%)$ & $7(10.1 \%)$ & $20(25.0 \%)$ & \\
\hline Anesthesia & & & & .032 \\
\hline Conscious sedation & $68(45.6 \%)$ & $38(55.1 \%)$ & $30(37.5 \%)$ & \\
\hline General anesthesia & $81(54.4 \%)$ & $31(44.9 \%)$ & $50(62.5 \%)$ & \\
\hline
\end{tabular}

${ }^{a}$ Quantitative variables are expressed as means; qualitative variables are expressed as numbers (corresponding percentage). 
$51.4 \%$ for the entire population. The model predicted up to $100 \%$ poor prognosis in patients who had a DWI lesion volume of $>80 \mathrm{~mL}$ and age older than 75 years, or DWI lesion volume of $>80 \mathrm{~mL}$ and time to groin puncture of $>4$ hours. A baseline NIHSS score of $>14$ provided additional information when the DWI lesion volume was $\leq 80 \mathrm{~mL}$, increasing prediction of poor

Table 2: Variables independently associated with poor prognosis identified in logistic regression analysis

\begin{tabular}{lcc}
\hline \multicolumn{1}{c}{ Variables } & $\begin{array}{c}\text { Odds Ratio } \\
(95 \% \mathrm{Cl})\end{array}$ & $\begin{array}{c}\boldsymbol{P} \\
\text { Value }\end{array}$ \\
\hline DWI lesion volume $>80 \mathrm{~mL}$ & $37.47(4.62-303.63)$ & .0007 \\
NIHSS score $>14$ & $5.84(2.20-15.52)$ & .0004 \\
Age older than $75 \mathrm{yr}$ & $6.15(2.35-16.11)$ & .0002 \\
Time from stroke onset to groin & $2.55(1.02-6.39)$ & .0456 \\
$\quad$ puncture (hr) & & \\
\hline
\end{tabular}

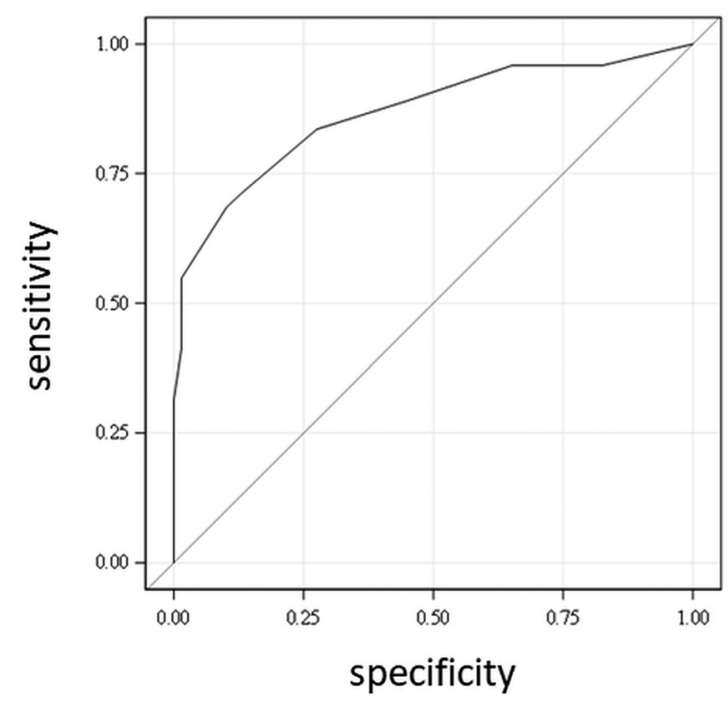

FIG 2. Receiver operating characteristic curve of the logistic model for prediction of poor prognosis: area under curve $=0.87$. prognosis from $19.1 \%$ to $56.3 \%$. When age older than 75 years and time from stroke onset to groin puncture of $>4$ hours were added, it allowed prediction of $100 \%$ of poor prognosis cases.

\section{DISCUSSION}

Our study identified prethrombectomy DWI lesion volume as a crucial predictor of disability at 3 months. DWI lesion volume of $>80 \mathrm{~mL}$, baseline NIHSS score of $>14$, age older than 75 years, and time from stroke onset to groin puncture of $>4$ hours were 4 identified independent risk factors of decreasing importance associated with poor prognosis at 3 months after thrombectomy. On this basis, we developed a hierarchic predictive algorithm for the likelihood of disability with a high predictive value (area under the curve, 0.87 ). The importance of using this type of prediction tool in clinical practice was illustrated by the $53.7 \%$ of patients with disability we observed, in full agreement with literature data (54.0\% in HERMES meta-analysis ${ }^{2}$ ).

We present a novel tool combining DWI with clinical data for predicting the risk of disability after thrombectomy. Most published prognostic clinical decision tools for identifying patients who may or may not benefit from intra-arterial treatment involved $\mathrm{CT}^{10,12}$ and showed that a low CT-ASPECTS $\left(\leq 7^{13}\right.$ or $\leq 5^{18}$ ) was associated with worse outcome. However, DWI proved to be more accurate than CT for predicting poor outcome because area under the curve scores for DWI-ASPECTS and lesion volume were higher $(0.70)$ than those of noncontrast or postcontrast CT $(0.55)^{14}$ and more accurate than perfusion CT for predicting good outcome (area under the curve, 0.58). ${ }^{19,20}$ Then studies increasingly focused on MR imaging to select patients. ${ }^{3,21-24}$ Then, an ancillary study of the THRACE trial reported that lesion volume was an independent predictor of disability because the number of patients needed to treat to achieve functional independence increased with lesion volume (10 patients for a volume of $80 \mathrm{~mL}, 15$ for $135 \mathrm{~mL}$ ), but no treatment-

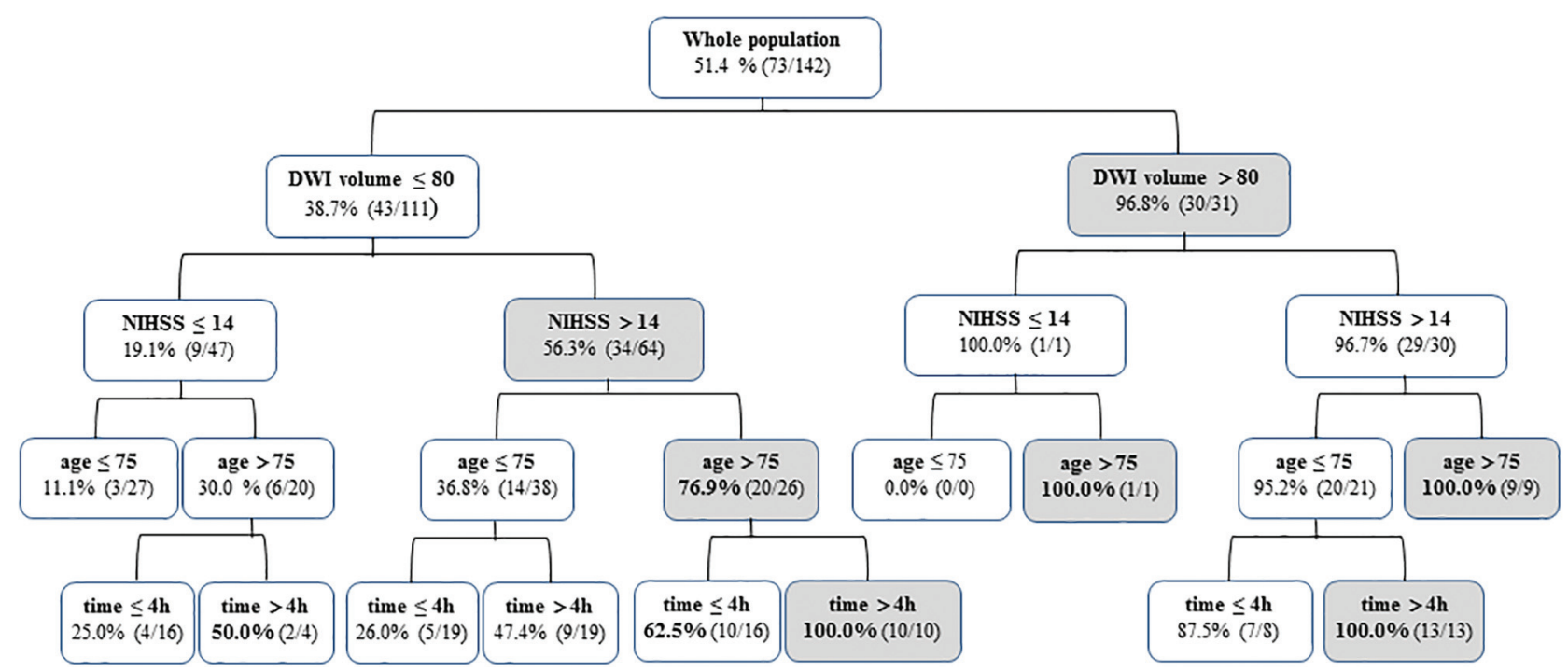

FIG 3. Hierarchic algorithm based on the 4 independent variables from the multivariate analysis for predicting poor prognosis at 3 months after thrombectomy. The algorithm shows the percentage of poor prognoses (mRS $>2$ at 3 months) predicted with the model and the corresponding number of cases observed in our population. 
by-dichotomized volume interaction for functional independence was observed. ${ }^{17}$

Our statistical method extracted cutoff values from receiver operating characteristic curves and identified a volume of $80 \mathrm{~mL}$ as having the best sensitivity and specificity for predicting poor outcome. The DWI-ASPECTS was not identified in the multivariate analysis due to the close association with DWI lesion volume, but a threshold of $<5$ was identified from the receiver operating characteristic curve after univariate analysis as predicting poor outcome. Both of these threshold values are in line with the latest Society of Neurointerventional Surgery guidelines, considering thrombectomy for class I level of evidence A indications in patients with anterior circulation acute stroke within 6 hours and either MR imaging DWI-ASPECTS of $\geq 6$ or a small DWI lesion of $<50-70 \mathrm{~mL}^{25}$ There is controversy in the literature about treating patients with large infarct core volumes. Recent studies showed up to $25 \%{ }^{21}$ to $34 \%{ }^{22}$ good outcomes in patients with a DWI-ASPECTS of $\leq 5$, particularly in young patients. ${ }^{23}$ Our study corroborates the benefit of thrombectomy, given the $15.2 \%$ chance of good outcome in patients with a DWI-ASPECTS of $\leq 5$. However, a patient with a DWI lesion of $>80 \mathrm{~mL}$ has only a $3.2 \%$ chance of good outcome, suggesting that this variable is more efficient than DWI-ASPECTS for triage decisions.

We identified older age and a high baseline NIHSS score as the strongest predictive variables after DWI lesion volume. Most studies have illustrated the important role of both these predictors of poor outcome at 3 months. ${ }^{10-12,14,17,26,27}$ We considered an age threshold of older than 75 years as predictive of disability, which is in accordance with literature data that identified an age between 65 and 80 years. ${ }^{10,13,28}$ The previously published baseline NIHSS threshold is variable from $>10^{28}$ to $>20,,^{27,28}$ which is also in accordance with our results $(>14)$. Time delay from stroke onset to groin puncture was identified as the least significant predictor of poor outcome, ranking fourth in our model, but it allowed predicting $100 \%$ of poor outcomes for patients with a DWI lesion volume of $>80 \mathrm{~mL}$ and age 75 years or younger, or for patients with DWI lesion volume of $\leq 80 \mathrm{~mL}$, an NIHSS score of $>14$, and age older than 75 years. The literature is contradictory as to the prognostic value of a longer time to thrombectomy. It was shown to be a poor prognostic factor ${ }^{26,27}$ by some authors, while others highlighted its modest ${ }^{10}$ or insignificant association $^{12,29}$ with prognosis. This difference questions the decision not to treat patients due to a longer time from stroke onset, especially with lesion volume of $\leq 80 \mathrm{~mL}$ and/or age 75 years or younger, especially in patients who need to be transferred to an intervention center, ${ }^{30}$ or for patients beyond a common therapeutic window $^{8}$ or with an unknown stroke onset time. ${ }^{29}$

Our hierarchic algorithm did not retain as significant certain variables such as systolic blood pressure or history of ischemic stroke or diabetes mellitus, which were identified in previous studies but with different population characteristics. ${ }^{10}$ For example, our patients had a shorter time to groin puncture (234 versus 260 minutes $^{10}$ ) and a higher percentage of effective recanalization ( $82 \%$ versus 59\%). This high successful recanalization rate of $75 \%$ for the patient group with poor outcome may also explain why this variable did not emerge as a significant prognostic factor. Last, collaterals were not evaluated in our MR imaging-based algorithm due to a lack of well-validated scales. Yet collaterals are a compensatory phenomenon, and their absence is presumed to be associated with larger core infarct volumes and poor prognosis. ${ }^{31}$

The proposed hierarchic algorithm is based on the DWI lesion volume and 3 clinical predictors with cutoff values and is very easy to use in clinical practice to predict the lack of clinical benefit of thrombectomy. Its predictive value is higher than in most previous scores proposed, with an area under the curve of 0.87 , and 0.75 for the HIAT2 score ${ }^{13}$ and 0.79 for the Pittsburgh Response to Endovascular Therapy score. ${ }^{12}$ Again, this superior result may be explained by the use of MR imaging instead of CT, given that MR imaging is the most accurate and validated method for assessing acute stroke lesions. Other factors such as the use of newer thrombectomy devices and earlier time to recanalization may also explain this higher predictive value. The limitations of our study lie in its retrospective nature and relatively small sample size, especially for subgroups of patients combining $>2$ risk factors. Additionally, 61 patients were excluded due to missing 3month mRS scores. Last, in the patient subgroup with DWI volumes of $>80 \mathrm{~mL}$, the addition of the NIHSS score, age, and time to groin puncture adds very little predictive value to the algorithm (96\% compared with 100\%). Further validation cohort studies are also needed to confirm the high predictive value.

\section{CONCLUSIONS}

Our study involved development of a hierarchic algorithm based on DWI lesion volume, age, baseline NIHSS score, and time to puncture for predicting disability at 3 months after thrombectomy with a high predictive value. This algorithm could help to design a clinical decision-making tool for better identification of patients for whom thrombectomy would be futile.

Disclosures: François Eugène-UNRELATED: Consultancy: BIOMODEX SAS. Sarah Evain-UNRELATED: Payment for development of educational presentations: CHEM, Comments: Private educational group for paramedical et medical formation; Travel/accommodations/meeting expenses unrelated to activities listed: SLCE group, Comments: SLICE meeting travel, accommodation, meeting. Thomas Ronziere-RELATED: Support for Travel to Meetings for the Study or Other Purposes: Shire, Genzyme.

\section{REFERENCES}

1. Lopez AD, Mathers CD, Ezzati M, et al. Global and regional burden of disease and risk factors, 2001: systematic analysis of population health data. Lancet 2006;367:1747-57 CrossRef Medline

2. Goyal M, Menon BK, van Zwam WH, et al. Endovascular thrombectomy after large-vessel ischaemic stroke: a meta-analysis of individual patient data from five randomised trials. Lancet 2016;387: 1723-31 CrossRef Medline

3. Bracard S, Ducrocq X, Mas JL, et al. Mechanical thrombectomy after intravenous alteplase versus alteplase alone after stroke (THRACE): a randomised controlled trial. Lancet Neurol 2016;15:1138-47 CrossRef Medline

4. Powers WJ, Rabinstein AA, Ackerson T, et al. 2018 Guidelines for the Early Management of Patients with Acute Ischemic Stroke: A Guideline for Healthcare Professionals From the American Heart Association/American Stroke Association. Stroke. 2018,49:e46e110 CrossRef Medline

5. Wahlgren N, Moreira T, Michel P, et al. Mechanical thrombectomy in acute ischemic stroke: Consensus statement by ESO-Karolinska 
Stroke Update 2014/2015, supported by ESO, ESMINT, ESNR and EAN. Int J Stroke 2016;11:134-47 CrossRef Medline

6. Alawieh A, Zaraket $\mathrm{F}$, Alawieh $\mathrm{MB}$, et al. Using machine learning to optimize selection of elderly patients for endovascular thrombectomy. J NeuroInterv Surg 2019;11:847-51 CrossRef Medline

7. Haussen DC, Lima FO, Bouslama M, et al. Thrombectomy versus medical management for large vessel occlusion strokes with minimal symptoms: an analysis from STOPStroke and GESTOR cohorts. J Neurointerv Surg 2018;10:325-29 CrossRef Medline

8. Nogueira RG, Jadhav AP, Haussen DC, et al. Thrombectomy 6 to 24 hours after stroke with a mismatch between deficit and infarct. $N$ Engl J Med 2018;378:11-21 CrossRef Medline

9. Nie X, Pu Y, Zhang Z, et al. Futile recanalization after endovascular therapy in acute ischemic stroke. Biomed Res Int 2018;2018:879548 CrossRef Medline

10. Venema E, Mulder M, Roozenbeek B, et al. Selection of patients for intra-arterial treatment for acute ischaemic stroke: development and validation of a clinical decision tool in two randomised trials. BMJ 2017;357:j1710 CrossRef Medline

11. Hallevi $\mathrm{H}$, Barreto $\mathrm{AD}$, Liebeskind $\mathrm{DS}$, et al. Identifying patients at high risk for poor outcome after intra-arterial therapy for acute ischemic stroke. Stroke 2009;40:1780-85 CrossRef Medline

12. Rangaraju S, Aghaebrahim A, Streib C, et al. Pittsburgh Response to Endovascular therapy (PRE) score: optimizing patient selection for endovascular therapy for large vessel occlusion strokes. $J$ Neurointerv Surg 2015;7:783-88 CrossRef Medline

13. Sarraj A, Albright $\mathrm{K}$, Barreto $\mathrm{AD}$, et al. Optimizing prediction scores for poor outcome after intra-arterial therapy in anterior circulation acute ischemic stroke. Stroke 2013;44:3324-30 CrossRef Medline

14. Han M, Choi JW, Rim NJ, et al. Cerebral infarct volume measurements to improve patient selection for endovascular treatment. Medicine (Baltimore) 2016;95:e4702 CrossRef Medline

15. Huisa BN, Neil WP, Schrader R, et al. Clinical use of computed tomographic perfusion for the diagnosis and prediction of lesion growth in acute ischemic stroke. J Stroke Cerebrovasc Dis 2014; 23:114-22 CrossRef Medline

16. Campbell BC, Majoie C, Albers GW, et al. Penumbral imaging and functional outcome in patients with anterior circulation ischaemic stroke treated with endovascular thrombectomy versus medical therapy: a meta-analysis of individual patient-level data. Lancet Neurol 2019;18:46-55 CrossRef Medline

17. Xie Y, Oppenheim C, Guillemin F, et al. Pretreatment lesional volume impacts clinical outcome and thrombectomy efficacy: pretreatment lesion volume and stroke outcome. Ann Neurol 2018;83: 178-85 CrossRef Medline

18. Kawiorski MM, Martínez-Sánchez P, García-Pastor A, et al. Alberta Stroke Program Early CT Score applied to CT angiography source images is a strong predictor of futile recanalization in acute ischemic stroke. Neuroradiology 2016;58:487-93 CrossRef Medline
19. Naylor J, Churilov L, Chen Z, et al. Reliability, reproducibility and prognostic accuracy of the Alberta Stroke Program Early CT Score on CT perfusion and non-contrast CT in hyperacute stroke. Cerebrovasc Dis 2017;44:195-202 CrossRef Medline

20. Raza SA, Barreira CM, Rodrigues GM, et al. Prognostic importance of CT ASPECTS and CT perfusion measures of infarction in anterior emergent large vessel occlusions. J Neurointerv Surg 2019;11: 670-74 CrossRef Medline

21. Panni P, Gory B, Xie Y, et al. Acute stroke with large ischemic core treated by thrombectomy: predictors of good outcome and mortality. Stroke 2019;50:1164-71 CrossRef Medline

22. Manceau PF, Soize S, Gawlitza M, et al. Is there a benefit of mechanical thrombectomy in patients with large stroke (DWI-ASPECTS S5)? Eur J Neurol 2018;25:105-10 CrossRef Medline

23. Daniere F, Lobotesis K, Machi P, et al. Patient selection for stroke endovascular therapy: DWI-ASPECTS thresholds should vary among age groups-insights from the RECOST study. AJNR Am J Neuroradiol 2015;36:32-39 CrossRef Medline

24. Leslie-Mazwi TM, Hirsch JA, Falcone GJ, et al. Endovascular stroke treatment outcomes after patient selection based on magnetic resonance imaging and clinical criteria. JAMA Neurol 2016;73:4349 CrossRef Medline

25. Mokin M, Ansari SA, McTaggart RA, et al. Indications for thrombectomy in acute ischemic stroke from Emergent Large Vessel Occlusion (ELVO): report of the SNIS Standards and Guidelines Committee. J Neurointerv Surg 2019;11:215-20 CrossRef Medline

26. Hussein HM, Saleem MA, Qureshi AI. Rates and predictors of futile recanalization in patients undergoing endovascular treatment in a multicenter clinical trial. Neuroradiology 2018;60:557-63 CrossRef Medline

27. Shi Z-S, Liebeskind DS, Xiang B, et al. Predictors of functional dependence despite successful revascularization in large-vessel occlusion strokes. Stroke 2014;45:1977-84 CrossRef Medline

28. Hussein HM, Georgiadis AL, Vazquez G, et al. Occurrence and predictors of futile recanalization following endovascular treatment among patients with acute ischemic stroke: a multicenter study. AJNR Am J Neuroradiol 2010;31:454-58 CrossRef Medline

29. Nagel S, Herweh C, Pfaff JA, et al. Simplified selection criteria for patients with longer or unknown time to treatment predict good outcome after mechanical thrombectomy. J Neurointer Surg 2019; 11:559-62 CrossRef Medline

30. Sablot D, Dumitrana A, Leibinger F, et al. Futile inter-hospital transfer for mechanical thrombectomy in a semi-rural context: analysis of a 6-year prospective registry. J Neurointerv Surg 2019;11:539-44 CrossRef Medline

31. Renú A, Laredo C, Montejo C, et al. Greater infarct growth limiting effect of mechanical thrombectomy in stroke patients with poor collaterals. J Neurointerv Surg 2019;11:989-93 CrossRef Medline 